\title{
RENAISSANCE OF THE RUINS - GIVE MODERN FUNCTIONALITY TO RURAL ARCHITECTURAL RELICS
}

\author{
${ }^{1}$ Xue KANG ${ }^{*},{ }^{2}$ Gabriella MEDVEGY,${ }^{3}$ Yufang ZHOU \\ ${ }^{1}$ Marcel Breuer Doctoral School, Faculty of Engineering and Information Technology \\ University of Pécs, Boszorkány u. 2, H-7624 Pécs, Hungary, e-mail: 250659063@qq.com \\ ${ }^{2}$ Department of Interior, Applied and Creative Design, Institute of Architecture \\ Faculty of Engineering and Information Technology, University of Pécs \\ Boszorkány u. 2, H-7624 Pécs, Hungary, e-mail: medvegygabriella@mik.pte.hu \\ ${ }^{3}$ School of Architecture, China Central Academy of Fine Arts, Huajiadinan Str. 8 \\ Chaoyang, Beijing, China, e-mail: zhouyufang@cafa.edu.cn
}

Received 20 December 2019; accepted 14 April 2020

\begin{abstract}
China has experienced rapid urbanization, and the countryside has been abandoned over the past few decades, with some of it left in ruins. Faced with the many challenges brought by urbanization, people are tired of traffic jams and polluted air, which is the disadvantages of urbanization and the countryside, is beginning to be re-recognized and explored with new possibilities. The countryside has become the front line of contemporary Chinese architectural practice. Architects, artists and other different roles try to realize the rebirth of the countryside in many aspects, such as nature and humanity, production and community, through architecture and space.
\end{abstract}

Keywords: Rural, Ruins, Possibility, Function, Renaissance

\section{Exordium}

In the 2018 Venice International Architecture Biennale, the China Pavilion, with the theme of 'Building a future countryside' [1], introduced to the world that the Chinese countryside is an open field with various possibilities and opportunities. In the corner of the exhibition is a story about the revival of the village of Louna.

Louna, an ancient Buyi minority village of 16 villages, has long sunk on the edge of China's urbanization [2]. Among them is a deserted village called 'Stonemason Village' (Fig. 1). Most of the houses in the village are beside the narrow winding mountain road on the upper edge of sinkhole in karst landform, and a few scattered houses are at the

\footnotetext{
${ }^{*}$ Corresponding Author
} 
bottom of sinkhole. The remaining thick stone walls prove that the village was once rich, and the cultural decoration of the ancestral hall in the interior reflects the prosperity of the village in the past. Stonemason village is a natural and cultural overlap of relics and unique cultural landscape heritage. On the premise of respecting nature and history, the team designed the deserted village into a livable tourist area (Fig. 2).

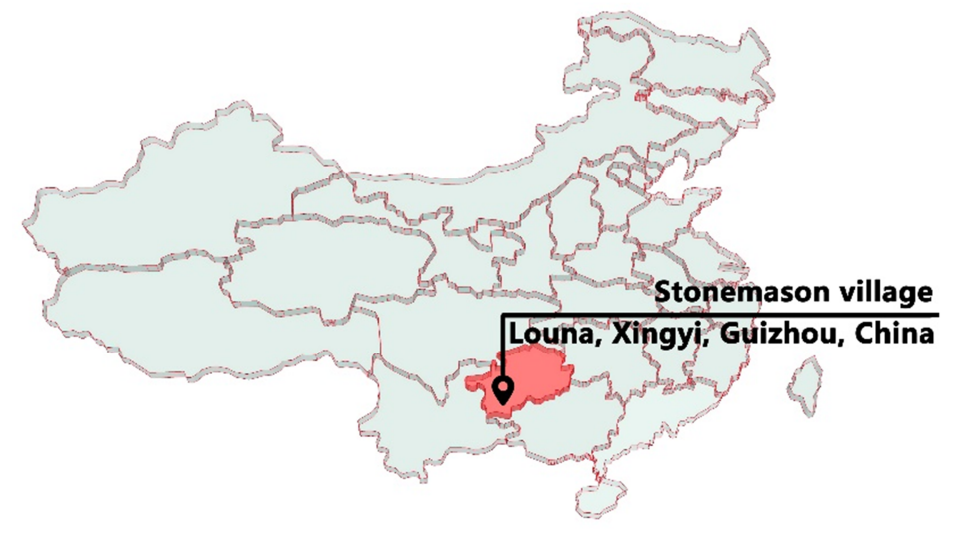

Fig. 1. Location of Stonemason village (Source: Drawing by Authors based on China map)
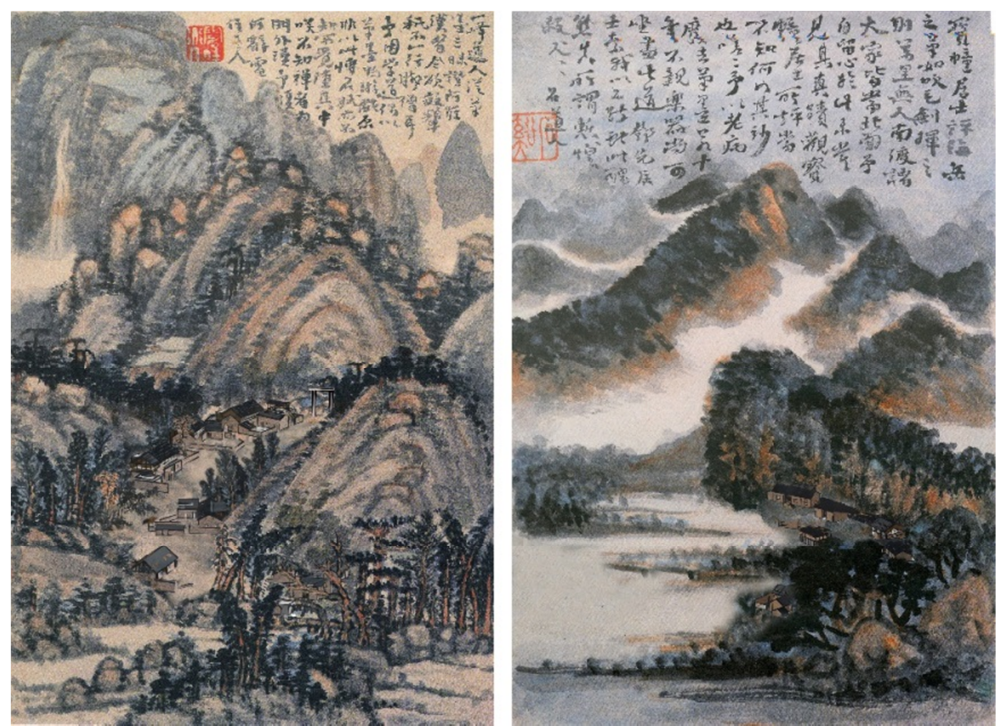

Fig. 2. Diagram of the Chinese painting style of the Stonemason village architectural design of the top and bottom zones of sinkhole (Source: Drawing by Author)

The humanism of regionalism and localism, combined with the functional pattern of modernism, is a utopia built for the future countryside. Karl Mannheim said: 'Today's 
utopia is likely to be tomorrow's reality. All sorts of utopian thoughts are merely truth of premature delivery' [3].

\section{Methodology}

The design of rural buildings is different from that of cities, based on changes in economic environment and social needs [4]. As a traditional village with distinctive culture and landscape, Stonemason village adheres to several basic methodologies in the process of rural architecture design. Through the diversity of functional types and participation roles and ways, the design realizes a process of both exporting and learning from the countryside, and to some extent, realizes the 'rebuild' and 'revival' of the concept of 'local construction'(Fig. 3).

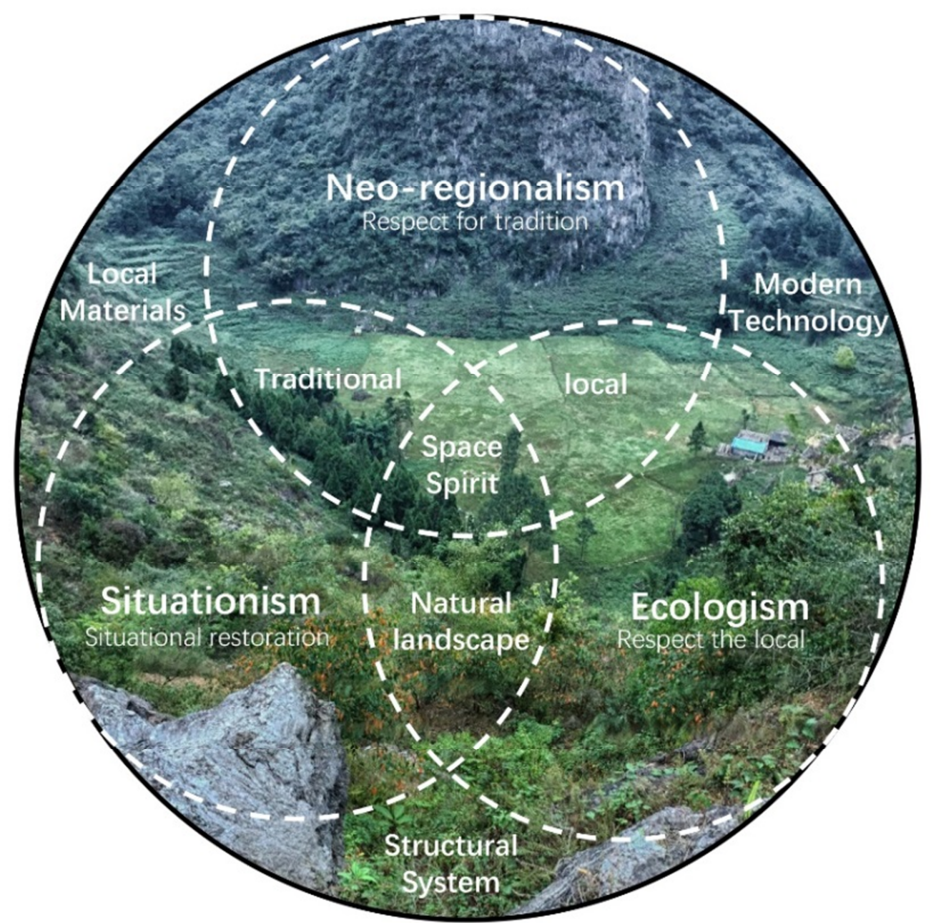

Fig. 3. Diagram of methodology (Source: Drawing by X. Kang)

\subsection{Neo-regionalism}

Neo-regionalism [5] is the transition from traditional regionalism to critical regionalism [6] (Fig. 4). It certainly comes from traditional localism or provincialism because it respects tradition and locality. However, neo-regionalism is not archaized or revivified, it also emphasizes the functionality and originality of modern architecture, 
which is the design architecture method of local characteristic combining modern technology. The new regionalism is more in line with the functional requirements of contemporary rural architecture than the traditional regionalism, and more inclusive and adaptable than critical regionalism.

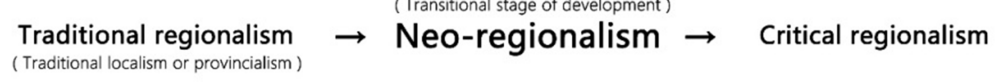

Fig. 4. The theoretical development diagram of Neo-regionalism (Source: Drawing by X. Kang)

\subsection{Situationism}

When it comes to Situationism, Situationist International becomes an unavoidable topic [7]. But situationism as a methodology is not a radical organization or historical event. There is no need to limit its boundaries with traditional art, politics or architectural science. Situationism emphasizes that 'constructed situation' and 'game society' are vague and open, but it is perfectly consistent with contemporary society's emphasis on 'immersive' and 'experiential' space design. The situation of restoring life does not represent an intact copy, but a reference to an innovative restoration design that resonates with contemporary life. This is very close to the commercial film as a kind of popular art, compared with the literary film is more easily understood and accepted by the people. The spirit or idea of design is conveyed more effectively and strongly through the method of situationism.

\subsection{Ecologism}

Inspired by the pressure of global ecological crisis and the stimulation of modern environmental movement, the goal of ecologism is to build a world of harmonious development between human society and natural environment. It is like architecture without an architect, architecture is an eternal art form of human wisdom, necessity and collective creativity, which strips away the intrinsic 'utilitarian' behavior [8]. That is also a sustainable, circular concept of development. Ecologism emphasizes the respect and reverence for nature and transforms the environment in a way that conforms to nature [9]. In the design of Stonemason village, respect for nature and conforms to the natural environment are the most effective methods.

\section{Characteristics of the Stonemason village case}

It is not so much the characteristics of the case design of the village of Louna Stonemason, but also the difficulty of design to explain it more appropriately. But at the same time, challenges come with opportunities. How to make the ruins of the abandoned rural re-used and popular at present? This is a process of using the wisdom 
of architects to make people understand the culture of rural areas and make rural buildings meet the needs of modern life.

\subsection{Minority cultures in the context of globalization}

Globalization, as a historical trend and a global phenomenon, has continuously penetrated into many fields of economy, politics and culture, and has greatly changed people's lives. One of the most fundamental characteristics of globalization is the global spread and construction of modernity. As a special cultural group, minorities face unprecedented opportunities and challenges in this historical trend.

Guizhou in southwest China is a province where many minorities live together. The Buyi are one of the larger minorities. The residents of Louna village, where the case is located, are all Buyi. The ancestors of the present villagers first settled here in the early Qing dynasty [10]. The unique geographical characteristics make minorities have a relatively weak position in cultural identity. The transformation of minority cultures towards modernization is the development of modern production methods, lifestyles, and cultural values that conform to globalization. The weakness of minority populations in the context of globalization can also be developed into their cultural 'special' advantages. This is an evolutionary process of self-preservation and self-innovation in the development of minority.

\subsection{Unique natural wonders}

The Stonemason village is located in a karst natural landscape consisting of nearly 20,000 mountain peaks. As a main type of karst surface morphology, hoodoo has extraordinary aesthetic value and is an outstanding example reflecting the earth's evolutionary history. The Stonemason village is relatively far from the center of Louna village, and traffic conditions are very unfavorable due to the unique natural topography (Fig. 5). Narrow and rugged roads limit the development of regional tourism resources (Fig. 6).

Since 2005, 'Tiankeng', a term defined by the Chinese, has gained consistent recognition in the international karst academic community, and the Chinese pinyin 'Tiankeng' has been adopted internationally. This is based on the discovery and research of the diverse sinkhole landscapes in southern China. The Stonemason village is located on the edge of tiankeng landscape. This is why the village sits in a linear settlement along the valley [11]. Under the limited terrain conditions, the layout of the village is divided into two parts: the top and the bottom of tiankeng, which also results in the construction scale of the village is not very large. At present, the remaining rural relics can be found above the tiankeng there are 9 households, the bottom of the tiankeng has 4 households.

The local natural landscape creates a unique natural environment for the village, which is an ornamental and artistic tourism resource. However, it is also the source of restricting the scale of village construction, transportation and material transmission and other tourism development conditions. How the specificity of landscape can overcome the limitation of development is a difficult problem raised by nature and also a gift prepared by nature. 

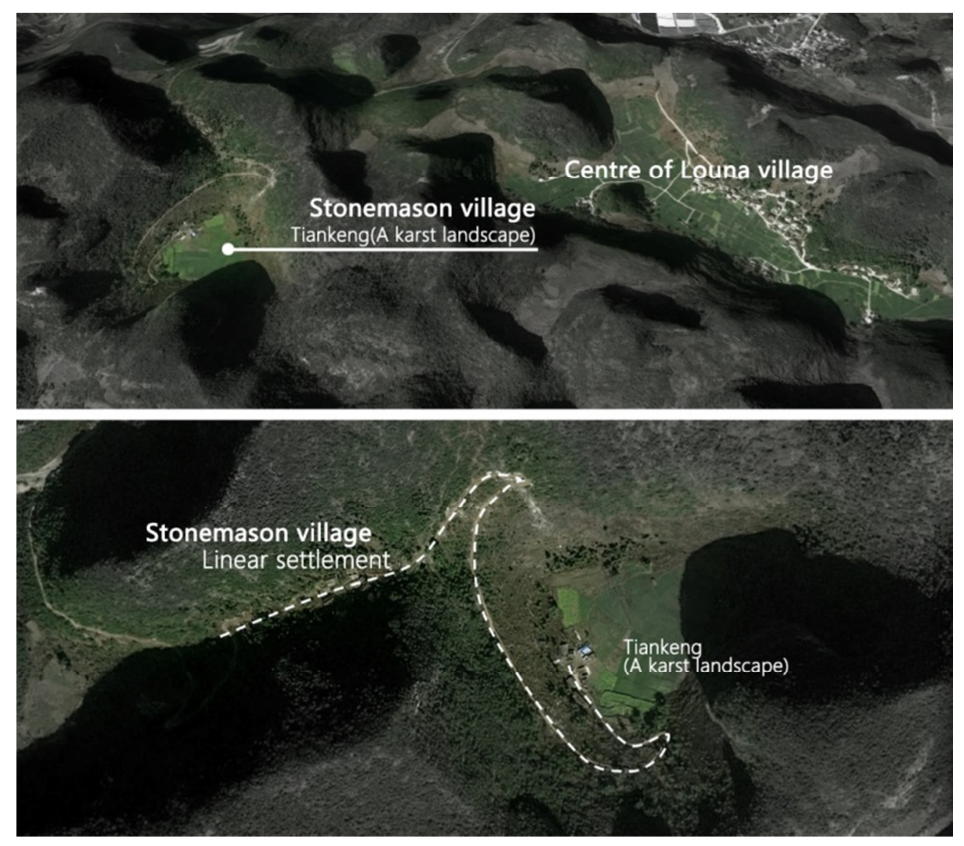

Fig. 5. Topography and traffic analysis of Stonemason village (Source: Drawing by X. Kang based on Google Earth)

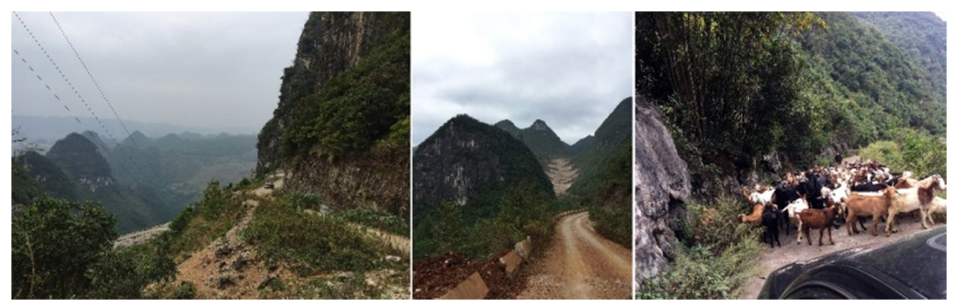

Fig. 6. Adverse road conditions into the village and the traffic jam caused by sheep herding (Source: Photographed by X. Kang)

\subsection{Ruins of a century-old village}

The status quo of Stonemason village is an abandoned, empty village site (Fig. 7). Rural buildings have been severely damaged due to prolonged desolation and have become uninhabitable. This village, which has a history of more than 140 years, was abandoned in the urbanization development of nearly two decades. Like the remains of the dilapidated and heavy stone walls, the architectural ruins of the village still have a primitive and natural beauty. Like the materials of this century-old rural building, the spirit of the place still exists [12]. The remains of the Stonemason village's buildings embody the technology and materials of more than a hundred years ago, silently telling 
the history and culture of the Stonemason village to visitors who first arrived at the village site.
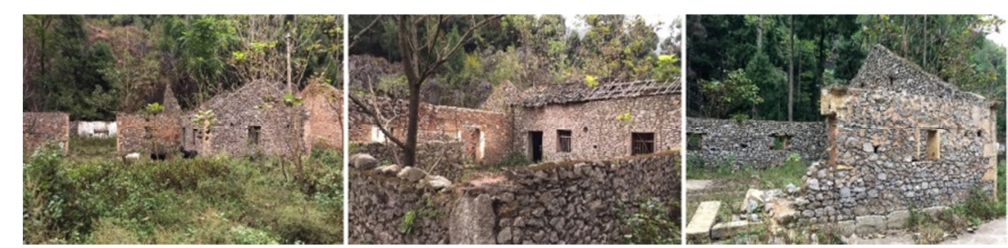

Fig. 7. Stonemason village field survey status (Source: Photographed by X. Kang)

The preservation and awe of the rural ruins, making the architectural design of the pressure multiplied. Whether the sense of shock that the place brings to humanity can be preserved through modern design and brings functions and experiences that are more adaptable to modern needs is the biggest challenge in the design of historical buildings or ruins. It is necessary not to let the heavy sense of history and the traces of contextualized life be eliminated by modern design, but it is also close to modern life, which in fact requires the design method of neo-regionalism and situationism [13].

\section{4. 'No man's land' without reference}

The unique national culture, the rare natural landscape and the contextualized architectural remains are all the design conditions that can be constantly imagined and created. But while Stonemason village has so much design freedom, it also represents a design difficulty that lacks purpose and reference.

This case is special because it is a 'no man's land'. Previous rural reconstruction projects were mostly hollow villages with some residents. Rural buildings are designed to take into account the wishes of the inhabitants. Although it makes the design process more complicated and design conditions more restrictive. But the design can be more realistic. In comparison, the Stonemason village is completely designed and defined by the architects. With design freedom the same worry about idealism comes. Whether the design of stonemason village as an immersive experience tourism area is the most appropriate positioning, there is a lack of reference from the local people.

\section{Explore the possibility of architecture ruins in rural}

The design principle of Stonemason village is to respect the tradition and the regional situation, modernizing the space of the building, but preserving its native character. The original plan of the village is preserved, emphasizing the addition of functional spaces and landscape nodes in the overall planning of the village (Fig. 8). For example, the addition of parking and village entrance landscaping. The overall layout of the village was also reconstructed according to the two divisions of the original site. In the two village building groups at the top and bottom of tiankeng, in addition to the residential function, it also includes reception and catering services (Fig. 9). The two groups are relatively independent but complementary 


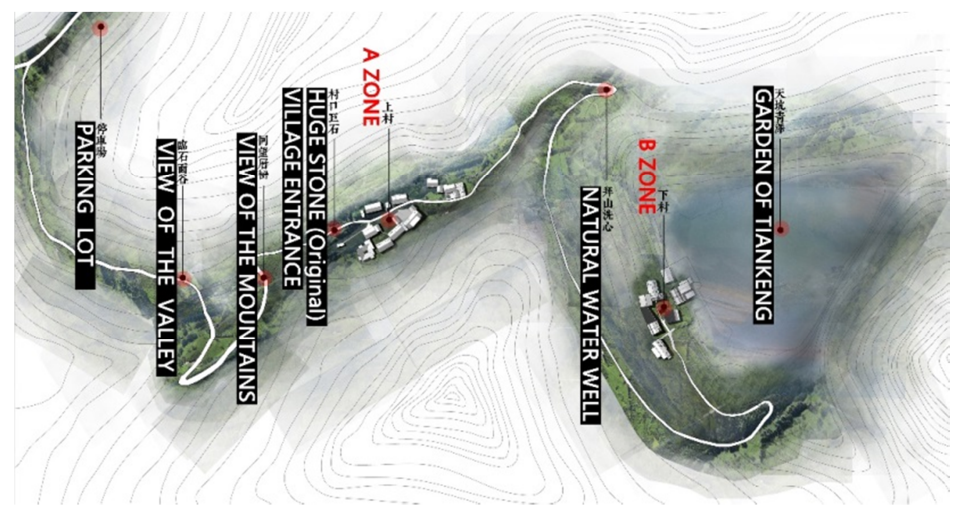

Fig. 8. The master plan for Stonemason village
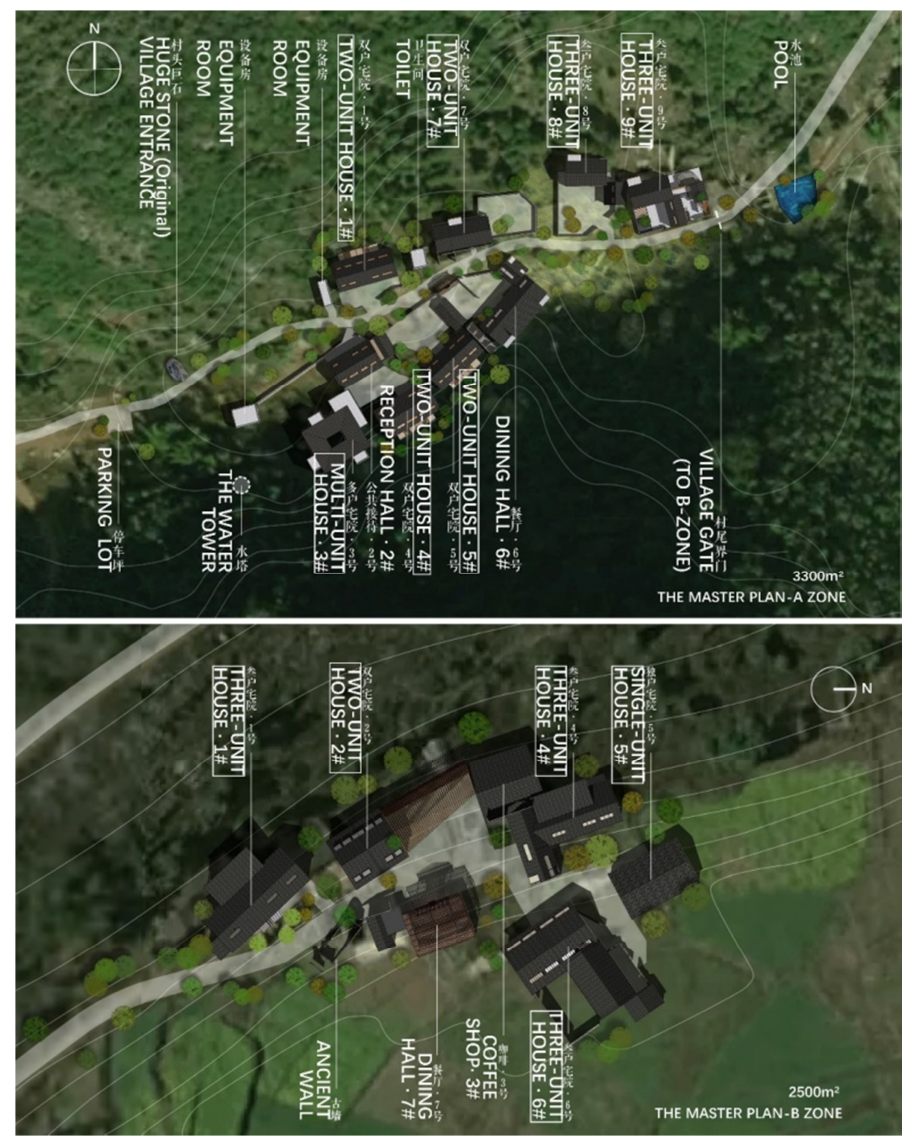

Fig. 9. The master plan of A and B zone of Stonemason village (Source: Drawing by Author)

Pollack Periodica 15, 2020, 3 
The specific way of design is to keep all the old walls, repair and supplement the incomplete buildings under the framework of the old buildings. In addition, the structure form of local traditional dwellings is continued, and the materials continue to use local stone to reduce the damage to nature as far as possible (Fig. 10). In the specific architectural decoration, the details of traditional decoration are simplified. The space is modern in function, and considering the architectural space can satisfy the multi-functional transformation. The space function can be residential, but also has the condition to change into service or other functions. For example, No. 6 in B zone is functionally positioned as a restaurant, but another residential function of the building is also prepared (Fig. 11). The richness and diversity of the architectural spaces can serve different types of guests. The flexibility to adapt the building's functions according to its usage is also a sustainable design.
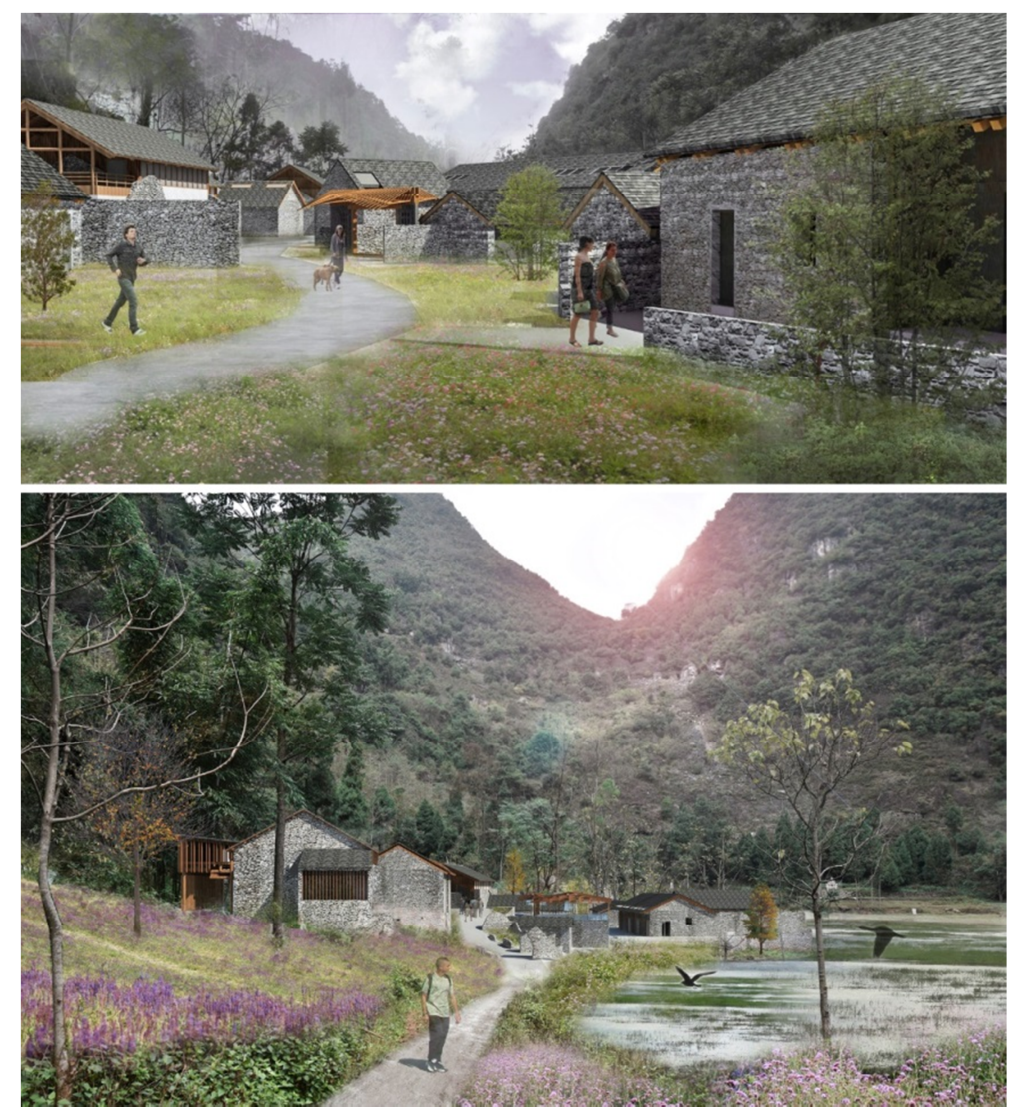

Fig. 10. Stonemason Village environment design renderings (Source: Drawing Author) 

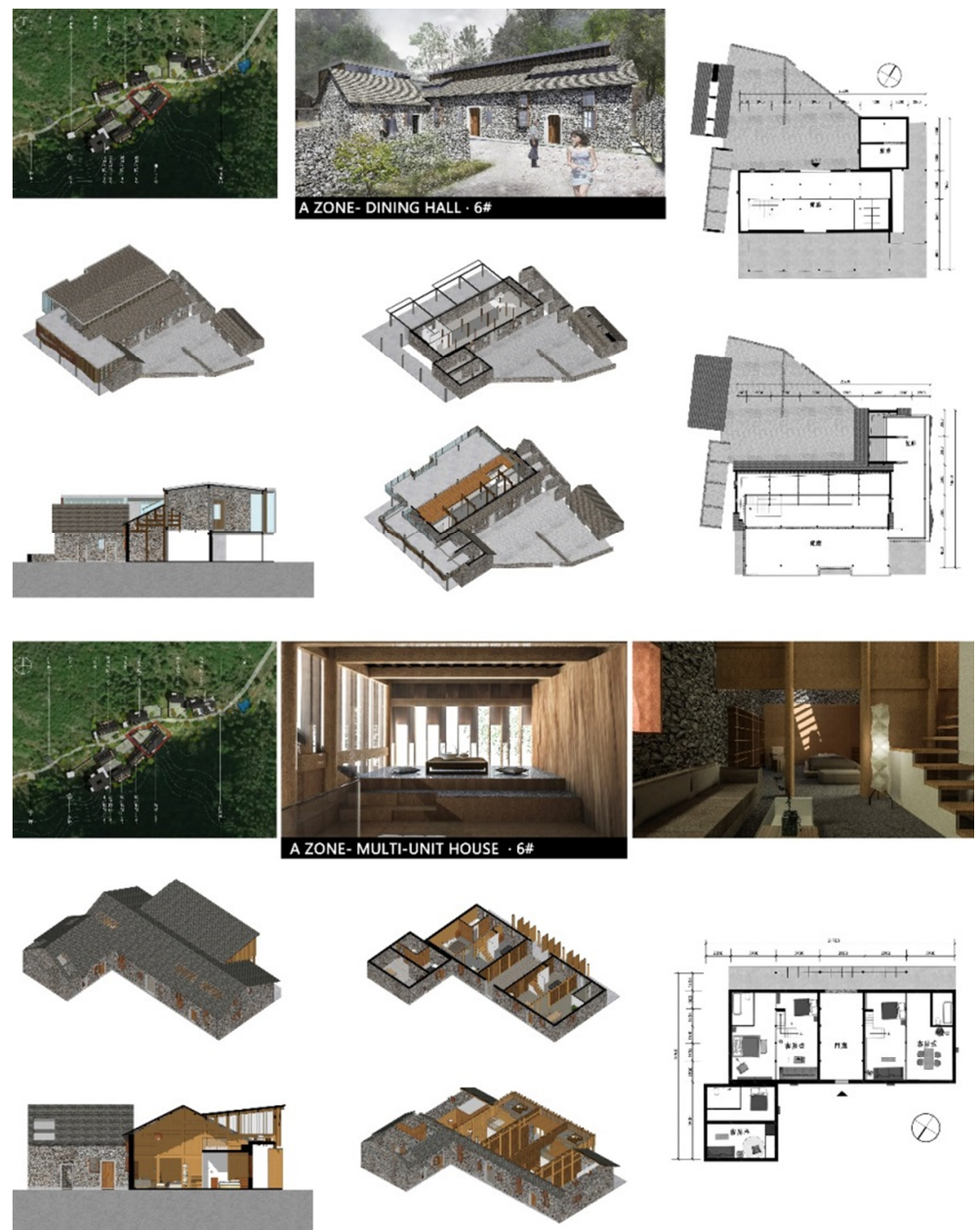

Fig. 11. Two design plans for No. 6 in zone B, (Source: Drawing by Author)

\section{Conclusion}

Memory allows human culture to continue. The revival of rural ruins is the hope that the development of rural architecture will heal mankind. The renaissance of rural ruins is to hope for the cure mankind by allowing the development of rural architecture by giving modern functions to architectural remains. In each era, there is a design language that belongs to the present; and in every tiny design detail, the most real life state of that era is hidden. When the space with 'people' as the main line development will produce a lot of fun, the original impossible, has become the source of drama. The smashed life scenes are harmoniously unified through the combination of spatial sequences, artistic 
association and processing, and immersive forms. This is the charm of local characteristic rural ruins.

The aesthetic reconstruction of villages should not simply pursue the appearance of buildings, but should try to express the activities of people living in them. This contains the satisfaction of the activity state brought by design, the guidance of life style, and the infiltration of culture and art. This is the attribute that space should have as the most loyal carrier of the times and regions, and also the goal of rural ruins Renaissance.

\section{Acknowledgements}

Thanks to the 'Urban Environmental Design' magazine for this meaningful design activity. Thanks to Prof. Zhou Yufang, deputy Dean of School of Architecture, China Central Academy of Fine Arts for giving authors the opportunity to participate in design projects. Thanks to the students Zhang Anxiang, $\mathrm{Xu} \mathrm{Zi}$, and Huang Cong from the School of Architecture of the China Central Academy of Fine Arts, and Dr. Yan Xin from the Center of Architecture Research and Design of University of Chinese Academy of Sciences who helped the authors during the research period.

\section{Open Access statement}

This is an open-access article distributed under the terms of the Creative Commons Attribution 4.0 International License (https://creativecommons.org/licenses/by/4.0/), which permits unrestricted use, distribution, and reproduction in any medium, provided the original author and source are credited, a link to the CC License is provided, and changes - if any - are indicated. (SID_1)

\section{References}

[1] Li X. N., Wanli M., Rebecca G. Architecture China: Building a future countryside, The Images Publishing Group, 2018.

[2] Peng L. X. Louna international architects' village: Design-led village vision, Liaoning Science and Technology Publishing House, 2018.

[3] Mannheim K. Ideology and utopia: An introduction to the sociology of knowledge, Martino Fine Books, 2015.

[4] Zhao D. P., Bachmann B., Wang T. Architecture and landscape design for Beikanzi village in China: An investigation of human settlement and environment, Pollack Periodica, Vol. 13, No. 2, 2018, pp. 231-236.

[5] Wang L. J., Shu P. Analysis of the frame of typology in contemporary western architecture, Architectural Journal, No. 8, 2005, pp. 8-21.

[6] Lefaivre L., Tzonis A. Critical regionalism: Architecture and identity in a globalized world, Prestel Publishing, 2003.

[7] Debord G. The society of the spectacle, Bureau of Public Secrets, 2014.

[8] Rudofsky B. Architecture without architects: A short introduction to non-pedigreed architecture, University of New Mexico Press, 1987.

[9] Gyergyak J., Ge D., Paari P. Concepts for waterfront developments, focusing on Siofok, Hungary, Pollack Periodica, Vol. 13, No. 1, 2018, pp. 169-179. 
[10] Buyi Society of Xingyi City., Xingyi Affairs Bureau of ethnic and religious., Xingyi Tourism Bureau of Culture \& Sports and Radio \& TV, Xingyi Buyi village, Guizhou Ethnic Publishing House, 2014.

[11] Wang Y. Spatial concept in traditional settlement structure, China Architecture \& Building Press, 2009.

[12] Norberg-Schulz C. Genius loci: Towards a phenomenology of architecture, Rizzoli, 1979.

[13] Rajković I., Bojović M. Revitalization of traditional architecture towards sustainable development of the Skadar Lake Area, Architecture and Urban Planning, Vol. 11, No. 1, 2016, pp. 32-42. 